\title{
Herring Bone Stitch: Knitting to Secure Abdominal Wall Closure for Emergency Midline Laparotomy
}

\author{
Reena Kothari, Ritu Thakur, Dhananjaya Sharma* and Pawan Agarwal \\ Department of Surgery, Government Medical College, India
}

*Corresponding author: Professor Dhananjaya Sharma, 602, Datt Residency, Near 2 ${ }^{\text {nd }}$ Railway Bridge, North Civil Lines, Jabalpur, Madhya Pradesh, India

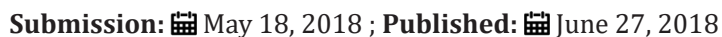

\begin{abstract}
Introduction: 5-26\% of patients develop incisional hernia (IH) after midline laparotomy. We hypothesized that a simple 'herring bone' stitch repair can provide secure abdominal wall closure and minimize the incidence of IH in patients undergoing emergency midline laparotomy.

Methods: This prospective observational study was done from March 2015 to December 2017 in a teaching hospital in Central India. Consecutive patients undergoing emergency midline laparotomy were included. Study group (patients undergoing single layer continuous herring bone closure of rectus sheath with Polypropylene no. 1 suture) was compared with control group (patients undergoing standard single layer continuous closure of rectus sheath with Polypropylene no. 1 suture). Patients were followed up till 1 year. Outcomes noted were surgical site infection (SSI), proline knot granuloma or sinus formation, superficial wound dehiscence, fascial dehiscence and IH.
\end{abstract}

Results: There were 112 patients in study group and 108 in control group with comparable demographics.Vector physics of Herring bone stitch showed that any tension on the suture line is preferentially distributed parallel to the wound. Incidence of SSI, proline knot granuloma and superficial wound dehiscence was comparable among the two groups. The incidence of fascial dehiscence (0.045) and IH was less ( $p=0.009)$ in study group.

Discussion: The Herring bone stitch is technically easy, reproducible, safe and can be performed quickly. The present study shows superiority of 'herring bone suture' over conventional closure of rectus sheath in emergency midline laparotomy.

Keywords: Emergency midline laparotomy; Abdominal wall closure; Incisional hernia; Herring bone stitch

\section{Introduction}

Secure abdominal wall closure after any laparotomy is every surgeon's aim. However, in spite of all scientific advancements, better suture materials and different/ modified closure techniques; $5-26 \%$ of patients develop incisional hernia (IH) after midline laparotomy [1-6]. This figure goes further up if high risk groups are analyzed separately or if the follow up is for a period longer than 3 years [7-10]. Surgeons have risen to this challenge and have tried different sutures, techniques and even prophylactic mesh placement; with varying degree of success. We hypothesized that a simple 'herring bone' stitch repair can provide secure abdominal wall closure and minimize the incidence of $\mathrm{IH}$ in patients undergoing emergency midline laparotomy.

\section{Methods}

This prospective observational 'proof of concept' study was done from March 2015 to December 2017 in a teaching hospital of Central India. Consecutive patients undergoing midline laparotomy in two different units in emergency setting were included. Patients younger than 14 years of age, those with previous midline surgical scar or incisional hernia were excluded. Control group consisted of patients who underwent standard single layer continuous closure of rectus sheath with Polypropylene no. 1 suture (Unit of DS) and Study group consisted of patients who underwent single layer continuous herring bone closure of rectus sheath with Polypropylene no. 1 suture (Unit of PA). Surgical procedures were done by Junior Consultant or Senior Registrar. The study was approved by the institutional ethical committee and due informed consent was taken from patients.

Patients' hemodynamic status and biochemical parameters were assessed at the time admission. A simple method was devised to consider if patient's values were normal or out of range. If patient's Systolic blood pressure was $<90 \mathrm{~mm}$ of $\mathrm{Hg}$ or needed vasopressor support, it was considered as out of range. Blood sample was taken at the time of admission and biochemical parameters, e.g., Hemoglobin, Blood Sugar, Serum Bilirubin, Serum 
Creatinine and Total Proteins were noted at the time of admission. Their normal range was considered as $10-16 \mathrm{gm} / \mathrm{dl}$, up-to $140 \mathrm{mg} /$ dl, $0.2-1.2 \mathrm{mg} / \mathrm{dl}, 0.7-1.4 \mathrm{mg} / \mathrm{dl}$ and $6-8 \mathrm{gm} / \mathrm{dl}$ respectively.

\section{Statistics}

The expected sample size was calculated a priori at 256 patients. The demographic data among the two groups were compared with the help of appropriate statistical tests: Z statistics was applied for comparison between two proportions where the sample size was large; Chi-square was applied for comparison of contingency tables (gender and diagnosis); Fischer's exact test was considered where frequency was less than 5; and Student $t$ test was applied to compare difference between two means where the sample size was small. Data were analyzed by IBM SPSS Statistics.

\section{Herringbone Technique}

Figure 1A: Diagrammatic representation of conventional continuous running suture.

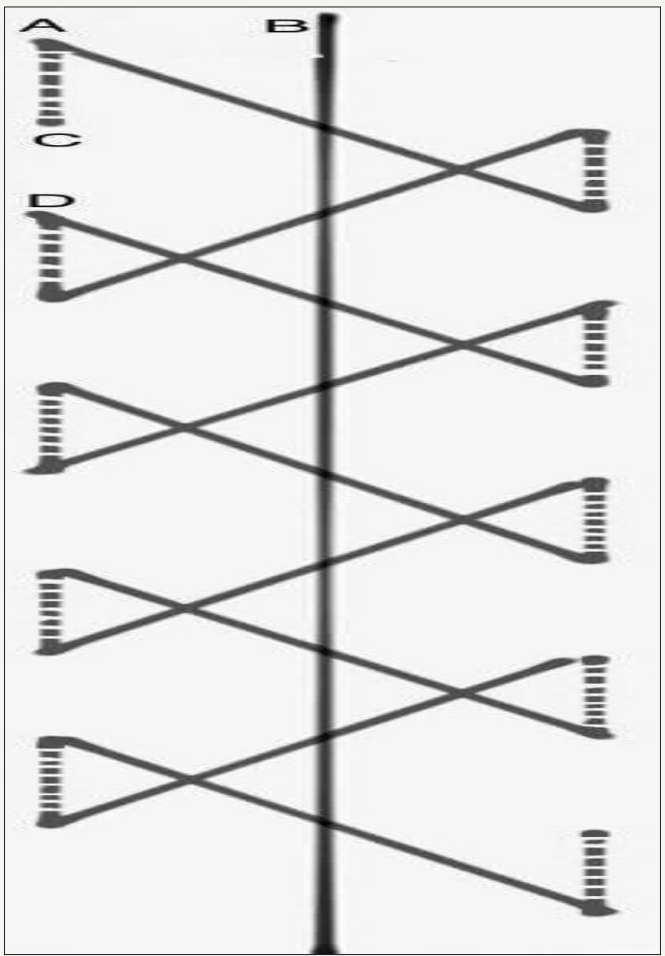

Figure 1B: Diagrammatic representation of Herring bone suture.

A-B $=1 \mathrm{~cm}$

$\mathrm{A}-\mathrm{C}=1 \mathrm{~cm}$

$\mathrm{C}-\mathrm{D}=1 \mathrm{~cm}$ 


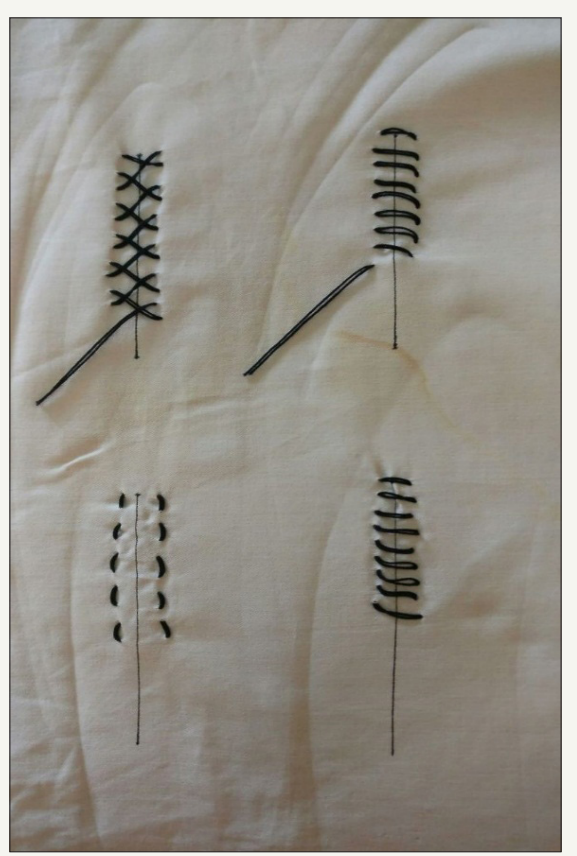

Figure 2: Conventional and Herring bone sutures applied on a piece of cloth.

Upper panel $=$ Superficial (skin side) view of conventional (right) and Herring bone sutures (left)

Lower panel $=$ Deep (undersurface) view of conventional (right) and Herring bone sutures (left)

The first stitch is taken from inside out then outside in so as to put the knot inside. The needle is passed $1 \mathrm{~cm}$ from the edge to take a $1 \mathrm{~cm}$ long bite parallel to the incision from distal to proximal direction. Next this suture goes to the opposite side across the midline to take a similar bite parallel to the previous one, again from distal to proximal direction. Similar procedure is repeated for each successive stitch (Figure $1 \mathrm{~A}-\mathrm{B}$ ). In this technique the suture does not cross the incision line on the peritoneal aspect; instead it crosses the midline over the anterior rectus sheath in a crisscross manner making a lattice of suture (Figure 2).

Patients were followed up post-operatively at regular intervals: at 1 week, at 2 weeks, at 6 weeks, at 6 months and at 1 year. Outcomes measured were surgical site infection (SSI), proline knot granuloma or sinus formation, superficial wound dehiscence (disruption of superficial wound but rectus repair intact), fascial dehiscence

Table 1: Preoperative demographics of patients. (complete disruption of wound with intra-abdominal contents/ intestines visible) and development of incisional hernia. Fascial dehiscence (burst abdomen) was not managed by primary repair in view of patient's emergency surgery but by secondary suturing and resulting IH was managed 6 months later when patient's condition was optimized. Only those patients were included in the analysis that completed one year of follow up.

\section{Results}

There were 112 patients in study group (mean age 46.99 years, range 18-73 years; 82 males and 30 females) and 108 in control group (mean age 36.81 years, range 21-67 years; 88 males and 20 females). Their hemodynamic status and laboratory parameters were comparable and are shown in (Table 1). CONSORT flow diagram of present study is shown as (Figure 3).

\begin{tabular}{|c|c|c|c|c|c|}
\hline Variables & Groups & Study group $(\mathrm{N}=112)$ & Control (N=108) & Statistical test & p-value \\
\hline \multirow{6}{*}{ Age } & $<20$ years & $3(2.68 \%)$ & $10(9.26 \%)$ & $\mathrm{z}=2.07$ & 0.04 \\
\hline & 20-30 years & $19(16.96 \%)$ & $33(30.56 \%)$ & $\mathrm{z}=2.37$ & 0.02 \\
\hline & $31-40$ years & $19(16.96 \%)$ & $27(25.00 \%)$ & $\mathrm{z}=1.46$ & 0.14 \\
\hline & $41-50$ years & $19(16.96 \%)$ & $20(18.52 \%)$ & $\mathrm{z}=0.30$ & 0.76 \\
\hline & $>50$ years & $52(46.43 \%)$ & $18(16.67 \%)$ & $\mathrm{z}=4.74$ & $<0.0001$ \\
\hline & mean \pm sd & $46.99 \pm 15.72$ & $36.81 \pm 13.83$ & $t=5.09$ & $<0.0001$ \\
\hline \multirow{2}{*}{ Gender } & Male & $82(73.21 \%)$ & $88(81.48 \%)$ & \multirow{2}{*}{$\mathrm{X} 2=2.14$} & \multirow{2}{*}{0.14} \\
\hline & Female & $30(26.79 \%)$ & $20(18.52 \%)$ & & \\
\hline \multicolumn{2}{|c|}{ Hemodynamic status (mean \pm sd) } & $10.5 .30 \pm 9.01$ & $10.4 .87 \pm 10.45$ & $t=0.33$ & 0.74 \\
\hline \multicolumn{2}{|c|}{ Hemoglobin g/dl (mean \pm sd) } & $11.05 \pm 1.59$ & $11.50 \pm 1.01$ & $\mathrm{t}=2.50$ & 0.01 \\
\hline \multicolumn{2}{|c|}{ Total protein (mean \pm sd) } & $6.55 \pm 1.00$ & $6.80 \pm 0.84$ & $\mathrm{t}=1.99$ & 0.05 \\
\hline
\end{tabular}




\begin{tabular}{|c|c|c|c|c|c|}
\hline \multicolumn{2}{|c|}{ Serum total bilirubin (mean \pm sd) } & $2.81 \pm 6.40$ & $2.52 \pm 5.98$ & $\mathrm{t}=0.34$ & 0.73 \\
\hline \multicolumn{2}{|c|}{ Serum creatinine (mean \pm sd) } & $0.92 \pm 0.35$ & $0.90 \pm 0.34$ & $\mathrm{t}=0.47$ & 0.64 \\
\hline \multirow{3}{*}{ Diagnosis } & Perforation peritonitis & $90(80.36 \%)$ & $88(81.48 \%)$ & \multirow{3}{*}{$X 2=5.23$} & \multirow{3}{*}{0.07} \\
\hline & Intestinal obstruction & $16(14.29 \%)$ & $12(11.1 \%)$ & & \\
\hline & Abdominal trauma & $6(5.36 \%)$ & $8(7.4 \%)$ & & \\
\hline
\end{tabular}

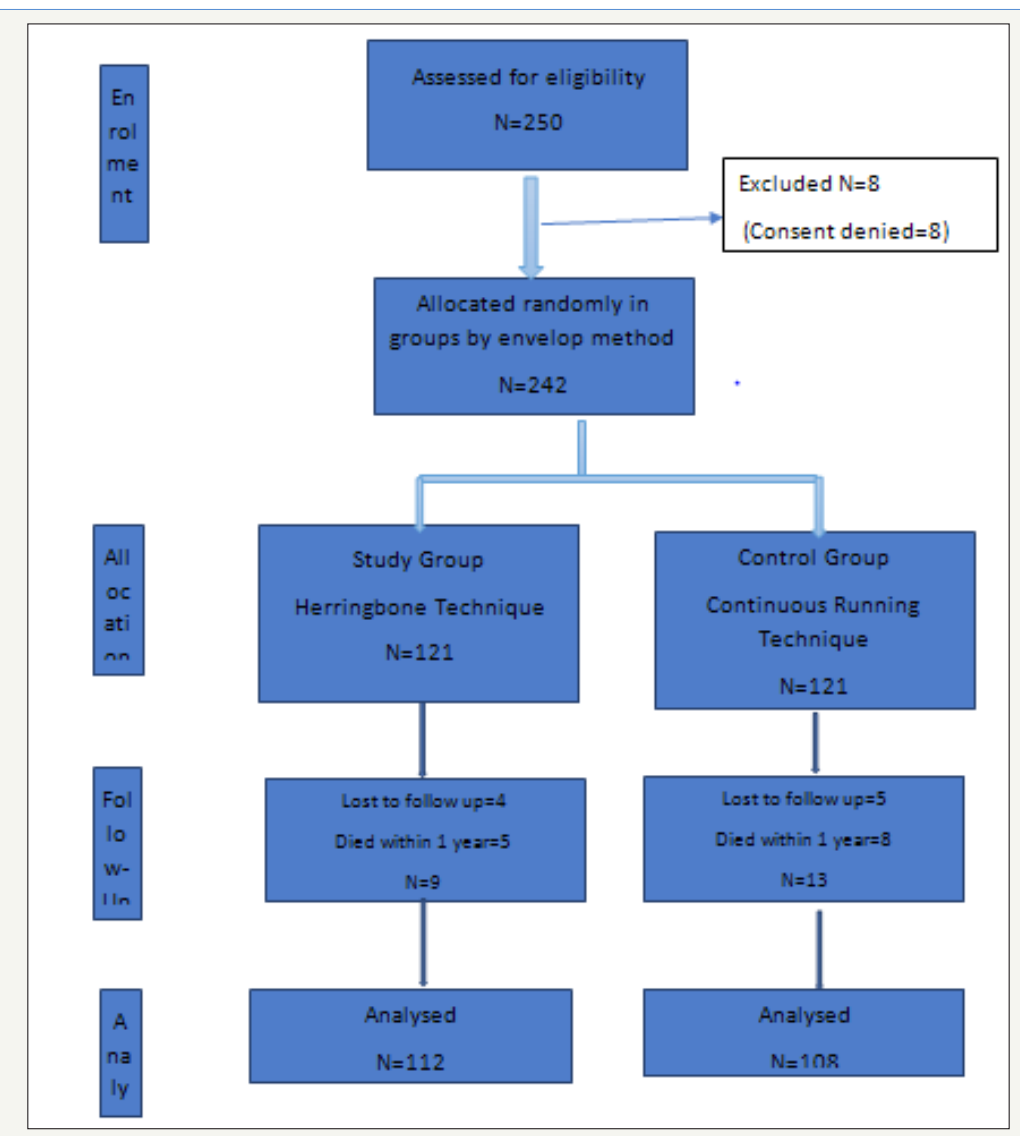

Figure 3: CONSORT flow diagram for the study.

More than $80 \%$ of cases in both groups had contaminated surgical wounds as $90 / 112(80.36 \%)$ of study group and 88/108 (81.48\%) of control group had perforation (peptic or typhoid) peritonitis. Other indications for emergency laparotomy were Intestinal obstruction (16/112 in study group and 12/108 in control group) and abdominal trauma (6/112 in study group and $8 / 108$ in control group). As expected, longer suture was required in the study group. The suture length to wound length ratio was $6.8: 1$ in study group and 4.3:1 in control group.

\section{Vector physics of herring bone stitch}

(Figure 4) shows a comparison of the herring bone suture geometry with the simple running suture geometry. Here, we designated the vertical axis to be parallel to the edges of the wound, and the horizontal axis runs across the cross-section of the wound. Using this formalism, we qualitatively evaluated the effective direction of the force experienced by any bite point in the tissue through which the suture is threaded. Assuming that the tension throughout the suture is constant and equal, any point in the tissue " $\mathrm{A}$ " will experience a force that is a vectorial combination of the tension vectors along " $\mathrm{AB}$ " and "AC", oriented at an angle $\theta$ with respect to each other. Due to the geometry of the herring bone pattern, the addition of these vectors results in an effective tension vector which is oriented at an angle $\varphi$ with respect to the vertical axis, parallel to the wound edge. However, for the simple running suture geometry, the effective tension vector is oriented at an angle $\varphi$ with respect to the horizontal axis. In the regime where $0<\theta<90^{\circ}$, we estimate that in all cases, $\varphi<45^{\circ}$. This suggests that in the herring bone suture geometry, the load will be preferentially distributed parallel to the wound boundary, whereas for simple running suture geometry, load will be directed laterally across the wound cross-section. The wound is expected to stretch laterally horizontally in (Figure 2) during any movement or breathing. For the same tension in the suture and the same angle $\theta$ between the sutures, the simple running suture geometry will provide more resistance to lateral expansion of the wound than the herring bone $\frac{\text { Horizontaltensioninsimplerunninggeometryatpoint } A}{\text { Horizontaltensionin herringbonegeometryatpoint } A}=$ resistanceratio $=\frac{1+\cos \theta_{\text {simple }}}{\cos \theta_{\text {herring }}}$ 


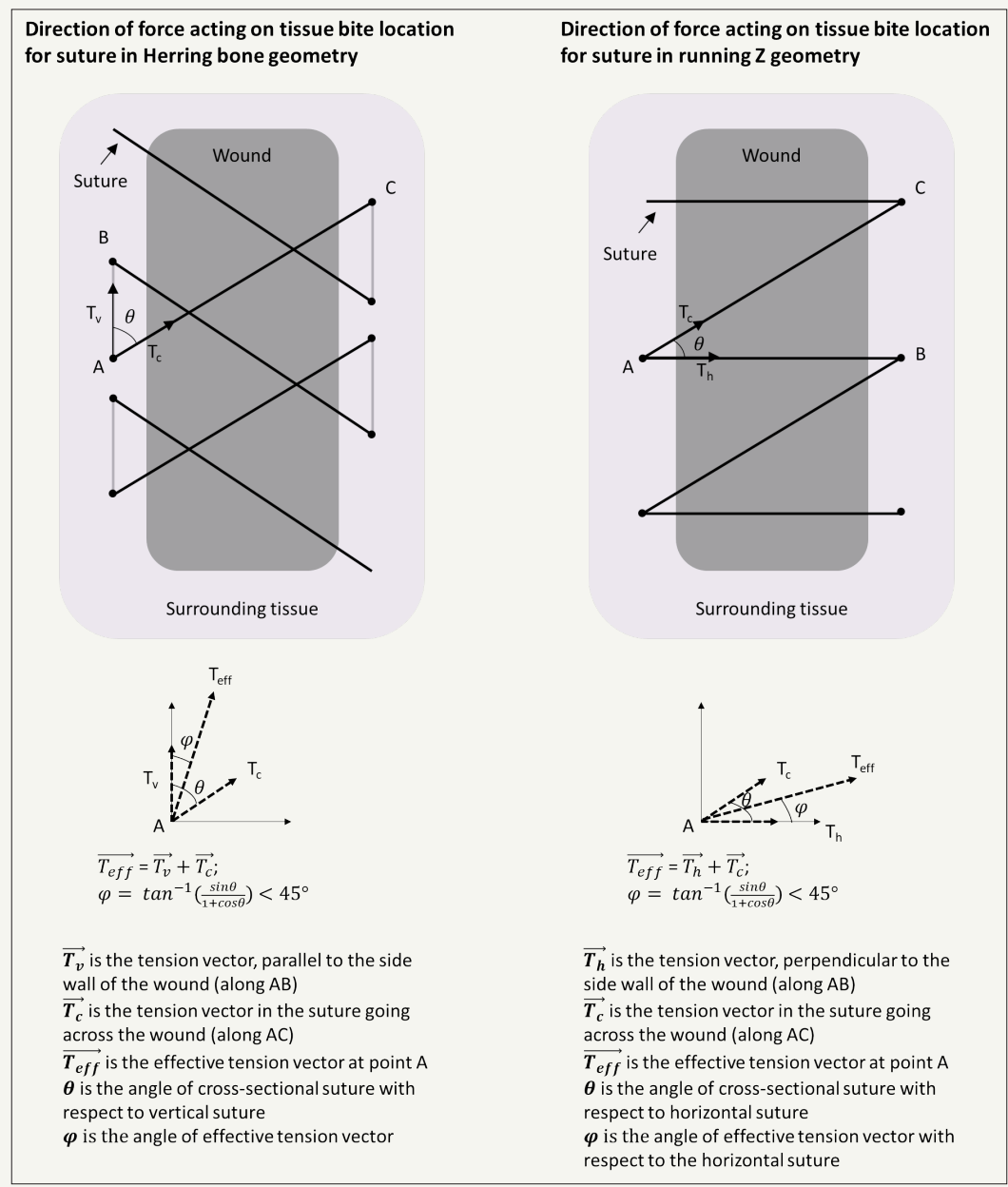

Figure 4: Vector physics of Herring bone suture (left) and conventional continuous running suture (right).

For the same nominal angle of $\theta_{-}$simple $=\theta_{-}$herring $=45^{\circ}$, the resistance ratio can be as much as 2.414 , or equivalently, the resistance experienced by the tissue can be up to $140 \%$ greater in the simple running geometry compared to the herring bone geometry. Based on this analysis, the herring bone suture is less likely to cut through the tissue during lateral expansion than the simple running suture.

Table 2: Outcome in study and control groups.

\begin{tabular}{|c|c|c|c|c|c|c|c|c|c|}
\hline Outcome & Group & N (\%) & 1 week & 2 week & 6 week & 6 month & 1 year & $\mathrm{X} 2$ & p-value \\
\hline \multirow{2}{*}{ Surgical site infection } & Study group $(\mathrm{N}=112)$ & 15 (13.39) & 10 & 5 & & & & \multirow{2}{*}{2.4} & \multirow{2}{*}{0.12} \\
\hline & Control group (N=108) & $23(21.30)$ & 18 & 5 & & & & & \\
\hline \multirow{2}{*}{$\begin{array}{l}\text { Polypropylene knot gran- } \\
\text { uloma }\end{array}$} & Study group (N=112) & $1(0.89)$ & & & 1 & & & \multirow{2}{*}{0.38} & \multirow{2}{*}{0.62} \\
\hline & Control group (N=108) & $2(1.85)$ & & & 2 & & & & \\
\hline \multirow{2}{*}{$\begin{array}{l}\text { Superficial wound dehis- } \\
\text { cence }\end{array}$} & Study group $(\mathrm{N}=112)$ & $13(11.61)$ & 5 & 8 & & & & \multirow{2}{*}{4.43} & \multirow{2}{*}{0.035} \\
\hline & Control group (N=108) & $24(22.22)$ & 13 & 11 & & & & & \\
\hline \multirow{2}{*}{ Fascial dehiscence } & Study group $(\mathrm{N}=112)$ & $8(7.14)$ & 4 & 4 & & & & \multirow{2}{*}{4.03} & \multirow{2}{*}{0.045} \\
\hline & Control group (N=108) & $17(15.74)$ & 10 & 7 & & & & & \\
\hline \multirow{2}{*}{ Incisional hernia } & Study group $(\mathrm{N}=112)$ & $3(2.68)$ & & & & 1 & 2 & \multirow{2}{*}{7.14} & \multirow{2}{*}{0.009} \\
\hline & Control group (N=108) & $13(12.04)$ & & & & 8 & 5 & & \\
\hline
\end{tabular}




\section{Discussion}

A midline incision is frequently used in abdominal surgery as it providesa relatively quick and wide access to the abdominal cavity with minimal damage to the muscle, nerve and bloodvessels as these sructures do not cross the midline. Risk factors for development of IH after midline laparotomy are well documented: male gender, age $>60$ years, preoperative anemia, BMI $>25$, non-elective admission, co-morbidities, previous laparotomy, bowel surgery, creation of an ostomy, type of suture, suture to wound length ratio $<4$, wound infection, wound dehiscence, postoperative pulmonary problems, postoperative abdominal distension/ intestinal obstruction, postoperative catecholamine-therapy and disturbed wound healing [7,11-17]. Incisional hernia risk prediction models have been constructed by statistically combining these risk factors [18-21].

Most risk factors are patient-related and surgeons do not have any control over them. This knowledge has affected the attitudes of surgeons and has given rise to different practices (types of suture and suturing techniques) to minimize IH. These include: debates about the optimum suture length, continuous Vs interrupted sutures, absorbable Vs slow absorbable Vs non-absorbable sutures, etc; but consensus among surgeons was slow to arrive [22-24]. It was left to the landmark systemic review and meta-analysis by Diener et al. to conclude that using a continuous (vs. interrupted) technique (OR: 0.59; $\mathrm{P}=0.001$ ) with slowly absorbable (vs. rapidabsorbable) suture material (OR: 0.65; $\mathrm{P}=0.009$ ) was best in the elective setting; and no further trials should be conducted for evaluation of technique and available materials for 'elective' midline abdominal fascial closure [4].

More complex closure techniques like interrupted ' $\mathrm{X}$ ' sutures, interrupted Smead-Jones sutures with or without a non-absorbable suture material for closure of linea alba combined with mass closure involving all the layers; also with a non-absorbable suture material; have been tried in the past [25-27]. Currently, a trial is going on using the 'Hughes Repair', which combines a standard mass closure with a series of horizontal and two vertical mattress sutures within a single suture [28]. This, theoretically, distributes the load along the incision length as well as across it. But this involves the use of two sutures, has the risk of bowel trapping and risk of suture entanglement, takes longer time, longer suture, and adds to the cost.

Wound infection (SSI) is the most important single factor raising the risk of development of IH by $2-10$ times $[11,15,29]$. In an attempt to minimize SSI, investigators have tried using braided suture materials with antibacterial activity, but it did not result in decreasing the incidence of $\mathrm{IH}$ [30]. A long stitch length is associated with an increase in the rate of wound infection and IH [31]. Another significant factor is wound dehiscence, which is almost invariably followed by IH; regardless of suture material or technique of repair $[14,29]$. It has been emphasized that it is not the type of suture, but the technique of suturing which determines the outcome as there was no significant difference in IH rate between absorbable and non-absorbable sutures [32-34]. However, Polypropylene is found to be associated with more persistent wound pain and more sinus formation as compared to Vicryl [14,22,35].

Concerns about unacceptably high IH rates have led to some 'out of box' thinking about secure abdominal wall closure. These include use of prophylactic retention sutures, use of rectus sheath relaxation incisions, as well as studies on histology and arterial perfusion of abdominal wall, novel plasma proteins as biomarkers for the development of incisional hernias and suture tension dynamics [36-40]. In the last few years investigators' focus has been on 'small tissue bites of $5 \mathrm{~mm}$ every $5 \mathrm{~mm}$ ' and use of prophylactic mesh placement to minimize IH. From small comparative studies to large multicenter Randomized Control Trials and systemic reviews - all have shown that both these techniques reduce the incidence of IH [31,41-47]. Recent success of small stitch trial has questioned the traditional guideline of 4-4.9:1 relationship between suture and wound length, as it requires a much longer suture and does not add to the risk of SSI and IH as was previously thought $[33,48]$.

The authors' reluctance to use a foreign body, i.e., a mesh in emergency situations in patients with potentially contaminated cases (perforation peritonitis, intestinal obstruction) led to hypothesizing that a simple 'herring bone' stitch repair can provide secure abdominal wall closure and minimize the incidence of IH in high risk emergency cases. Alexis Carrel, widely considered the father of vascular surgery for developing the technique of vascular anastomosis, was awarded Nobel Prize in Medicine in 1912 for his pioneering work which paved the path for organ transplantation. His interest in embroidery, piqued in childhood by watching his mother, led him to learn use of tiny needles and thread which later led to the development of his technique of vascular anastomosis [49]. Taking an inspirational leaf out of Carrel's book, authors had earlier applied the art of Tatting (lace making) to develop a simple, inexpensive, easy to use and safe technique of extracorporeal knotting [50]. In the present study, the inspiration came from the art of knitting, embroidery, and crochet and led to use of Herring bone stitch for secure abdominal wall closure.

The literal meaning of 'Herring bone' is a pattern consisting of columns of short parallel lines with all lines in onecolumn, sloping one way and all thelines inthenext column sloping the other way; is so named as it resembles the bones extending from the spine of a herring fish. Herring bone stitch has many advantages. This technique relies on each successive suture to reduce the tension on the stitch for the next suture to be passed. Herring bone suturing technique has the advantage of both continuous and cross suture method. The suture does not cross the midline on the peritoneal aspect thus avoiding the trauma to the moving gut loops by wiring effect. Instead the suture crosses the midline over the anterior rectus sheath in a crisscross manner making a network of suture giving the additional advantage of darning effect.

This leads to new fibrous tissue being laid down in the interstices of darn which strengthens the repair. Additionally, vector physics has shown that the herring bone suture is less likely to cut through the tissue during lateral expansion than the 
simple running suture (Figure 2). This is due to the fact that any tension on the suture line is preferentially distributed parallel to the wound boundary and can better accommodate any increase in the intra-abdominal pressure in the post-operative period. There is additional advantage of burying the knot inside the rectus sheath as it theoretically leads to decreased incidence of stitch granulomas. It is technically easy, reproducible, safe and can be performed quickly.

Our results in emergency setting in relatively high risk $(>80 \%$ patients had perforation peritonitis, had anaemia: $30 \%$ in study group and $27 \%$ in control group, hypoproteinaemia: $23 \%$ in study group and $25 \%$ in control group, raised bilirubin: $44 \%$ in study group and $40 \%$ in control group. (Table 1) patient cohorts go in favour of our hypothesis. Despite using polypropylene, knot granuloma was seen in only 1 patient in study group and in 2 patients in control group. Other complications (SSI, and superficial wound dehiscence) were comparable among the two groups. The incidence of fascial dehiscence $(7.14 \%$ as compared to $15.74 \%$; $\mathrm{p}=0.045)$ and incisional hernia was significantly less $(2.68 \%$ as compared to $12.04 \% ; p=0.009$ ) in study group (Table 2). Fascial dehiscence and IH have similar causative factors; but fascial dehiscence occurring within 2 weeks of emergency surgery reflects more about the patient related factors (anemia, hypoproteinemia, intraabdominal sepsis, post-operative abdominal distention, chest infection etc.) while IH occurring much later is more reflective of abdominal closure technique $[12,25]$.

The present study shows superiority of 'herring bone suture' over conventional closure of rectus sheath in emergency midline laparotomy. However, there are a few limitations of our study: Small numbers of patients have been studied in the two arms and the follow-up period is only 1 year. It is known that the incidence of IH increases with the duration of follow up; only about a third of IH develop in the first 6 months after the operation, $54.4 \%$ after 12 months, $74.8 \%$ after 2 years and $88.9 \%$ after 5 years [7]. Hence validation of this hypothesis in larger number of patients, followed up for longer period will strengthen the evidence.

\section{References}

1. Israelsson LA (1998) The surgeon as a risk factor for complications of midline incisions. Eur J Surg 164(5): 353-359.

2. Mingoli A, Puggioni A, Sgarzini G, Luciani G, Corzani F, et al. (1999) Incidence of incisional hernia following emergency abdominal surgery. Ital J Gastroenterol Hepatol 31(6): 449-453.

3. Liapis CD, Dimitroulis DA, Kakisis JD, Nikolaou AN, Skandalakis P, et al. (2004) Incidence of incisional hernias in patients operated on for aneurysm or occlusive disease. Am Surg 70(6): 550-552.

4. Diener MK, Voss S, Jensen K, Büchler MW, Seiler CM (2010) Elective midline laparotomy closure: the INLINE systematic review and metaanalysis. Ann Surg 251(5): 843-856.

5. Le Huu Nho R, Mege D, Ouaïssi M, Sielezneff I, Sastre B (2012) Incidence and prevention of ventral incisional hernia. J Visc Surg 149(5 Suppl): e3-e14.

6. Fink C, Baumann P, Wente MN, Knebel P, Bruckner T, et al. (2014) Incisional hernia rate 3 years after midline laparotomy. Br J Surg 101(2): 51-54.

7. Höer J, Lawong G, Klinge U, Schumpelick V (2002) Factors influencing the development of incisional hernia. A retrospective study of 2,983 laparotomy patients over a period of 10 years. Chirurg 73(5): 474-480.

8. Mudge M, Hughes LE (1985) Incisional hernia: a 10 year prospective study of incidence and attitudes. Br J Surg 72(1): 70-71.

9. Moussavian MR, Schuld J, Dauer D, Justinger C, Kollmar O, et al. (2010) Long term follow up for incisional hernia after severe secondary peritonitis-incidence and risk factors. Am J Surg 200(2): 229-234.

10. Itatsu K, Yokoyama Y, Sugawara G, Kubota H, Tojima Y, et al. (2014) Incidence of and risk factors for incisional hernia after abdominal surgery. Br J Surg 101(11): 1439-1447.

11. Irvin TT, Stoddard CJ, Greaney MG, Duthie HL (1977) Abdominal wound healing: a prospective clinical study. Br Med J 2(6083): 351-352.

12. Bucknall TE, Cox PJ, Ellis H (1982) Burst abdomen and incisional hernia: a prospective study of 1129 major laparotomies. Br Med J (Clin Res Ed) 284(6320): 931-933.

13. Israelsson LA, Jonsson $T$ (1996) Incisional hernia after midline laparotomy: a prospective study. Eur J Surg 162(2): 125-129.

14. van't RM, De Vos Van Steenwijk PJ, Bonjer HJ, Steyerberg EW, Jeekel J (2004) Incisional hernia after repair of wound dehiscence: incidence and risk factors. Am Surg 70(4): 281-286.

15. Murray BW, Cipher DJ, Pham T, Anthony T (2011) The impact of surgical site infection on the development of incisional hernia and small bowel obstruction in colorectal surgery. Am J Surg 202(5): 558-560.

16. Yılmaz KB, Akıncı M, Doğan L, Karaman N, Özaslan C, et al. (2013) A prospective evaluation of the risk factors for development of wound dehiscence and incisional hernia. Ulus Cerrahi Derg 29(1): 25-30.

17.Walming S, Angenete E, Block M, Bock D, Gessler B, et al. (2017) Retrospective review of risk factors for surgical wound dehiscence and incisional hernia. BMC Surg 17(1): 19.

18. Veljkovic R, Protic M, Gluhovic A, Potic Z, Milosevic Z, et al. (2010) Prospective clinical trial of factors predicting the early development of incisional hernia after midline laparotomy. J Am Coll Surg 210(2): 210219.

19. Goodenough CJ, Ko TC, Kao LS, Nguyen MT, Holihan JL, et al. (2015) Development and validation of a risk stratification score for ventral incisional hernia after abdominal surgery: hernia expectation rates in intra-abdominal surgery (the HERNIA Project). J Am Coll Surg 220(4): 405-413.

20. Argudo N, Iskra MP, Pera M, Sancho JJ, Grande L, et al. (2017) The use of an algorithm for prophylactic mesh use in high risk patients reduces the incidence of incisional hernia following laparotomy for colorectal cancer resection. Cir Esp 95(4): 222-228.

21. Cherla DV, Moses ML, Mueck KM, Hannon C, Ko TC, et al. (2017) External Validation of the HERNIA score: An Observational Study. J Am Coll Surg 225(3): 428-434.

22. Hodgson NC, Malthaner RA, Ostbye T (2000) The search for an ideal method of abdominal fascial closure: a meta-analysis. Ann Surg 231(3): 436-442.

23. Gupta H, Srivastava A, Menon GR, Agrawal CS, Chumber S, et al. (2008) Comparison of interrupted versus continuous closure in abdominal wound repair: a meta-analysis of 23 trials. Asian J Surg 31(3): 104-114.

24. Rahbari NN, Knebel P, Diener MK, Seidlmayer C, Ridwelski K, et al. (2009) Current practice of abdominal wall closure in elective surgery - Is there any consensus? BMC Surg 9: 8.

25. Srivastava A, Roy S, Sahay KB, Seenu V, Arvind Kumar, et al. (2004) Prevention of burst abdominal wound by a new technique: A randomized trial comparing continuous versus interrupted X-suture. Ind J Surg 66 (1): 19-27.

26. Sivam NS, Suresh S, Hadke MS, Kate V, Ananthakrishnan N (1995) Results 
of the Smead-Jones technique of closure of vertical midline incisions for emergency laparotomies--a prospective study of 403 patients. Trop Gastroenterol 16(4): 62-67.

27. Murtaza B, Ali Khan N, Sharif MA, Malik IB, Mahmood A (2010) Modified midline abdominal wound closure technique in complicated/high risk laparotomies. J Coll Physicians Surg Pak 20(1): 37-41.

28. Cornish J, Harries RL, Bosanquet D, Rees B, Ansell J, et al. (2016) Hughes Abdominal Repair Trial (HART) - Abdominal wall closure techniques to reduce the incidence of incisional hernias: study protocol for a randomised controlled trial. Trials 17(1): 454.

29. Gislason H, Grønbech JE, Søreide O (1995) Burst abdomen and incisional hernia after major gastrointestinal operations-comparison of three closure techniques. Eur J Surg 161(5): 349-354.

30. Justinger C, Slotta JE, Schilling MK (2012) Incisional hernia after abdominal closure with slowly absorbable versus fast absorbable, antibacterial-coated sutures. Surgery 151(3): 398-403.

31. Millbourn D, Cengiz Y, Israelsson LA (2009) Effect of stitch length on wound complications after closure of midline incisions: a randomized controlled trial. Arch Surg 144(11): 1056-1059.

32. Israelsson LA, Jonsson T (1994) Closure of midline laparotomy incisions with polydioxanone and nylon: the importance of suture technique. $\mathrm{Br}$ ] Surg 81(11): 1606-1608.

33. Israelsson LA, Jonsson T (1997) Overweight and healing of midline incisions: the importance of suture technique. Eur J Surg 163(3): 175180.

34. Bosanquet DC, Ansell J, Abdelrahman T, Cornish J, Harries R, et al. (2015) Systematic Review and Meta-Regression of Factors Affecting Midline Incisional Hernia Rates: Analysis of 14,618 Patients. PLoS One 10(9): e0138745.

35. Chalya PL, Massinde AN, Kihunrwa A, Mabula JB (2015) Abdominal fascia closure following elective midline laparotomy: a surgical experience at a tertiary care hospital in Tanzania. BMC Res Notes 8: 281.

36. Khorgami Z, Shoar S, Laghaie B, Aminian A, Hosseini Araghi N, et al. (2013) Prophylactic retention sutures in midline laparotomy in highrisk patients for wound dehiscence: a randomized controlled trial. J Surg Res 180(2): 238-243.

37. Marwah S, Marwah N, Singh M, Kapoor A, Karwasra RK (2005) Addition of rectus sheath relaxation incisions to emergency midline laparotomy for peritonitis to prevent fascial dehiscence. World J Surg 29(2): 235239.

38. Höer J, Fischer L, Schachtrupp A (2011) Laparotomy closure and incisional hernia prevention - what are the surgical requirements? Zentralbl Chir 136(1): 42-49.

39. Böhm J, Pianka F, Stüttgen N, Rho J, Gigic B, et al. (2017) Discovery of novel plasma proteins as biomarkers for the development of incisional hernias after midline incision in patients with colorectal cancer: The Colo Care study. Surgery 161(3): 808-817.

40. Schachtrupp A, Wetter O, Höer J (2016) An implantable sensor device measuring suture tension dynamics: results of developmental and experimental work. Hernia 20(4): 601-606.

41. El-Khadrawy OH, Moussa G, Mansour O, Hashish MS (2009) Prophylactic prosthetic reinforcement of midline abdominal incisions in high-risk patients. Hernia 13(3): 267-274.

42. Bhangu A, Fitzgerald JE, Singh P, Battersby N, Marriott P, et al. (2013) Systematic review and meta-analysis of prophylactic mesh placement for prevention of incisional hernia following midline laparotomy. Hernia 17(4): 445-455

43. Caro-Tarrago A, Olona Casas C, Jimenez Salido A, Duque Guilera E, Moreno Fernandez F, et al. (2014) Prevention of incisional hernia in midline laparotomy with an onlay mesh: a randomized clinical trial. World J Surg 38(9): 2223-2230.

44. Deerenberg EB, Harlaar JJ, Steyerberg EW, Harlod E Lont, Helena C Van Doorn, et al. (2015) Small bites versus large bites for closure of abdominal midline incisions (STITCH): a double-blind, multicentre, randomised controlled trial. Lancet 386(10000): 1254-1260.

45. Borab ZM, Shakir S, Lanni MA, Tecce MG, MacDonald J et al. (2017) Does prophylactic mesh placement in elective, midline laparotomy reduce the incidence of incisional hernia? A systematic review and meta-analysis. Surgery 161(4): 1149-1163.

46. Tolstrup MB, Watt SK, Gögenur I (20-17) Reduced Rate of Dehiscence After Implementation of a Standardized Fascial Closure Technique in Patients Undergoing Emergency Laparotomy. Ann Surg 265(4): 821826.

47. Jairam AP, Timmermans L, Eker HH, Pierik REGJM, van Klaveren D, et al. (2017) Prevention of incisional hernia with prophylactic onlay and sublay mesh reinforcement versus primary suture only in midline laparotomies (PRIMA): 2-year follow-up of a multicentre, double-blind, randomised controlled trial. Lancet 390(10094): 567-576.

48. Israelsson LA, Jonsson T, Knutsson A (1996) Suture technique and wound healing in midline laparotomy incisions. Eur J Surg 162(8): 605609.

49. Savlania A (2017) Alexis Carrel: Father of Vascular Anastomosis and Organ Transplantation. Indian J Vasc Endovasc Surg 4 (3): 115-117.

50. Kothari R, Somashekar U, Sharma D, Thakur DS, Kumar V (2012) From Tatting to laparoscopy: a simple and safe knotting technique. Journal of Society of Laparoendoscopic Surgeon 16(2): 280-282.
Creative Commons Attribution 4.0

International License

For possible submissions Click Here

\section{Submit Article}

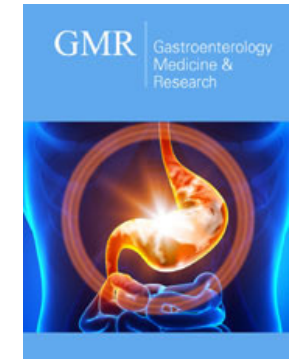

\section{Gastroenterology Medicine \& Research}

\section{Benefits of Publishing with us}

- High-level peer review and editorial services

- Freely accessible online immediately upon publication

- Authors retain the copyright to their work

- Licensing it under a Creative Commons license

- Visibility through different online platforms 